\title{
Изучение термодинамики сорбции некоторых производных бензимидазола из водно-метанольных растворов на гексадецилсиликагеле
}

\author{
Ядрова А.А., Писарева В.С., Шафигулин Р.В., Буланова А.В. \\ Самарский нащиональный исследовательский университет им. Академика С.П. Королева, Самара
}

Поступила в редакцию 2.05.2018 г.

DOI: https://doi.org/10.17308/sorpchrom.2018.18/559

В работе изучено влияние состава и природы элюента на удерживание биологически активных производных бензимидазола на гексадецилсиликагеле. В рамках модели Снайдера - Сочевинского рассмотрены зависимости фактора удерживания от структуры молекул. Оценены энергетические вклады различных заместителей в процесс сорбции, на основе разности изменений энергии Гиббса. На основании температурных зависимостей факторов удерживания исследуемых соединений рассчитаны энтальпия и энтропийная составляющая процесса сорбции.

Ключевые слова: высокоэффективная жидкостная хроматография, гексадецилсиликагель, бензимидазолы, термодинамика сорбции из жидких растворов, взаимосвязь «структура - свойство»

\section{Study of thermodynamic of certain benzimidazole deriva- tives sorption from water - methanol solutions on hexadecyl silica gel}

\author{
Yadrova A.A., Pisareva V.S., Shafigulin R.V., Bulanova A.V. \\ Samara National Research University, Samara
}

\begin{abstract}
The investigation of sorption from liquid solutions is an actual direction of modern science, both for the development of the fundamental foundations of the theory of sorption, and for the development of effective sorbents. The key aspect in the research of various structural classes compounds sorption is to analyze the relationship between structure and property, in which the influence of the structure of the compound on its sorption characteristics is manifested. Benzimidazoles and its derivatives are component part of an large amount of medications, therefore the investigation of their sorption from liquid solutions allows to determine the dynamics of their effect on the body and pharmacokinetics; to find methods of their eluting from biological fluids and to select the optimal conditions for extracting investigating compounds.

The experiment was carried out on a liquid chromatograph «MiliChrom A-02» with the UV spectrophotometric detector and a syringe pump in reversed-phase mode, using water methanol solutions as the eluent. The aim of this work was to analysis the benzimidazole derivatives sorption from various quantitative composition of water-methanol solutions, to determine the thermodynamic characteristics of sorption, and to establish the relationship «structure-property» within the framework of the Snyder-Sochevinsky model.

In this paper, the effect of the composition of water methanol solution on benzimidazoles sorption on the surface of hexadecyl silica gel was studied. The corresponding equations were obtained within the framework of the Snyder-Sochevinsky model. The energy contribution of different substituting groups in sorption process was estimated by applying Gibbs energy differences. The enthalpy and entropy component of sorption process were calculated and compensations for the bendimidazole derivatives on mobile phases with different contents of the organic modifier were studied. Indicated that two groups of sorbates are
\end{abstract}


isolated on the phase with $80 \%$ methanol content as it was connected with their different sorption mechanisms on hexadecylsilica gel.

Keywords: high performance liquid chromatography, hexadecyl silica gel, benzimidazole, thermodynamic of sorption from liquid solutions, interconnection "structure - properties"

\section{Введение}

Исследование сорбции из жидких растворов является актуальным направлением современной науки. Результаты этих исследований могут быть использованы для развития фундаментальных основ теории сорбции, разработки эффективных сорбентов для медицинских, экологических и других применений. Наиболее пригодным физико-химическим методом для исследования сорбции из жидких многокомпонентных растворов является высокоэффективная жидкостная хроматография (ВЭЖХ), где в качестве растворителя можно использовать элюенты различного качественного и количественного состава и осуществлять анализ широкого класса соединений без их предварительной модификации [1]. Для развития теории сорбции из жидких растворов необходимы знания о физико-химических характеристиках процесса. В работе определено относительное изменение свободной энергии Гиббса, рассчитаны энтальпия и вклад энтропийной составляющей в процесс сорбции производных бензимидазола. Важным моментом при изучении сорбции различных классов соединений является исследование взаимосвязи «структура - свойство», в которой проявляется влияние структуры соединения на его хроматографические и, следовательно, сорбционные характеристики [2-4]. Бензимидазолы и его производные входят в состав многих лекарственных средств, поэтому исследования их сорбции из жидких растворов позволяет устанавливать фармакокинетику и динамику их действия на организм; методы элюирования их из биологических жидкостей и т.д. Знание о термодинамических характеристиках сорбции позволяет подобрать оптимальные условия для извлечения исследуемых соединений из жидких растворов [58].

Целью настоящей работы явилось изучение сорбции производных бензимидазола из водно-метанольных растворов различного количественного состава, определение термодинамических характеристик сорбции, а также установление взаимосвязи «структура - свойство» в рамках вытеснительной модели Снайдера - Сочевинского.

\section{Теоретическая часть}

На основании результатов хроматографического эксперимента определяли факторы удерживания и термодинамические характеристики сорбции исследуемых соединений.

Фактор удерживания $k$ рассчитывали по формуле [9]:

$$
k=\frac{t_{R}-t_{M}}{t_{R}}
$$

где $t_{R}$ и $t_{M}$ - время удерживания исследуемого соединения и мертвое время, соответственно.

Разность изменений свободной энергии сорбции вещества і по отношению к сорбции стандартного вещества рассчитывали по формуле (2) [10]:

$$
\delta\left(\Delta G^{o}\right)_{i, s t}=-R T \ln \left(\frac{k_{i}}{k_{s t}}\right)
$$


где $T$ - температура $(\mathrm{K}) ; k_{i}$ - фактор удерживания исследуемого соединения; $k_{s t}$ фактор удерживания стандарта (в качестве стандартного вещества использовали бензимидазол).

Для описания удерживания производных бензимидазола в условиях жидкостной хроматографии применяли вытеснительную модель Снайдера-Сочевинского [11]. Эта модель предполагает, что однородная поверхность сорбента полностью покрыта молекулами органического модификатора или молекулами сорбата, и удерживание исследуемых соединений может быть описано следующим квазихимическим уравнением [9]:

$$
S_{m}+n \cdot X_{a} \leftrightarrow S_{a}+n \cdot X_{m}
$$

где $S$ - количество молекул сорбата; $X$ - количество молекул органического модификатора; $a$ и $m$ - относятся к неподвижной и подвижной фазам соответственно.

Модель Снайдера-Сочевинского следующим образом описывает зависимость хроматографического удерживания от концентрации полярного модификатора в элюенте можно описать с помощью уравнения [12]:

$$
\lg k=a-n \cdot \lg X_{m}
$$

где $k$ - это фактор удерживания, исследуемого аналита, $n$ - количество молекул органического модификатора, вытесняемое одной молекулой сорбата с поверхности адсорбента, $X_{m}$ - мольная доля более полярного компонента подвижной фазы.

Для расчета энтальпии и энтропии сорбции молекул, исследуемых бензимидазолов, использовали уравнение [13]:

$$
\ln k=-\frac{\Delta H^{o}}{R T}+\frac{\Delta S^{o}}{R}+\ln \varphi=-\frac{\Delta H^{o}}{R T}+A,
$$

где $\Delta H^{*}$ и $\Delta S^{*}$ - стандартные энтальпия и энтропия переноса бензимидазолов, а $\varphi-$ фазовое соотношение колонки, равное отношению объема сорбционной фазы к мертвому объему колонки $\left(\varphi=V_{s} / V_{M}\right) ; A$ - энтропийная составляющая процесса.

Рассмотрены термодинамические компенсационные эффекты между параметрами $\Delta H^{\circ}$ и $/ A /$, которые характеризуют сходство или не сходство физикохимических процессов сорбции исследуемых сорбатов в рассматриваемых системах. Компенсационный эффект выражается уравнением [9,14]:

$$
\Delta H^{o}=\beta \Delta S^{o}+\Delta G_{\beta}^{o},
$$

где $\Delta G_{\beta}^{o}$ - изменение свободной энергии физико-химических взаимодействий при температуре компенсации $\beta ; \beta$ - температура компенсации.

\section{Эксперимент}

Структурные формулы исследуемых бензимидазолов представлены в табл.1. Исследованные вещества синтезированы на кафедре органической, биоорганической и медицинской химии Самарского государственного университета. Структура и чистота соединений подтверждены ИК- и ЯМР-методами.

Таблица 1. Структуры исследованных производных бензимидазола

\begin{tabular}{|c|c|c|c|c|c|}
\hline № & Название & $\begin{array}{c}\text { Структурная форму- } \\
\text { ла }\end{array}$ & № & Название & $\begin{array}{c}\text { Структурная фор- } \\
\text { мула }\end{array}$ \\
\hline 1 & 2 & 3 & 4 & 5 & 6 \\
\hline 1 & Бензимидазол & & 8 & $\begin{array}{c}1-\text {-Бензилбенз- } \\
\text { имидазол }\end{array}$
\end{tabular}




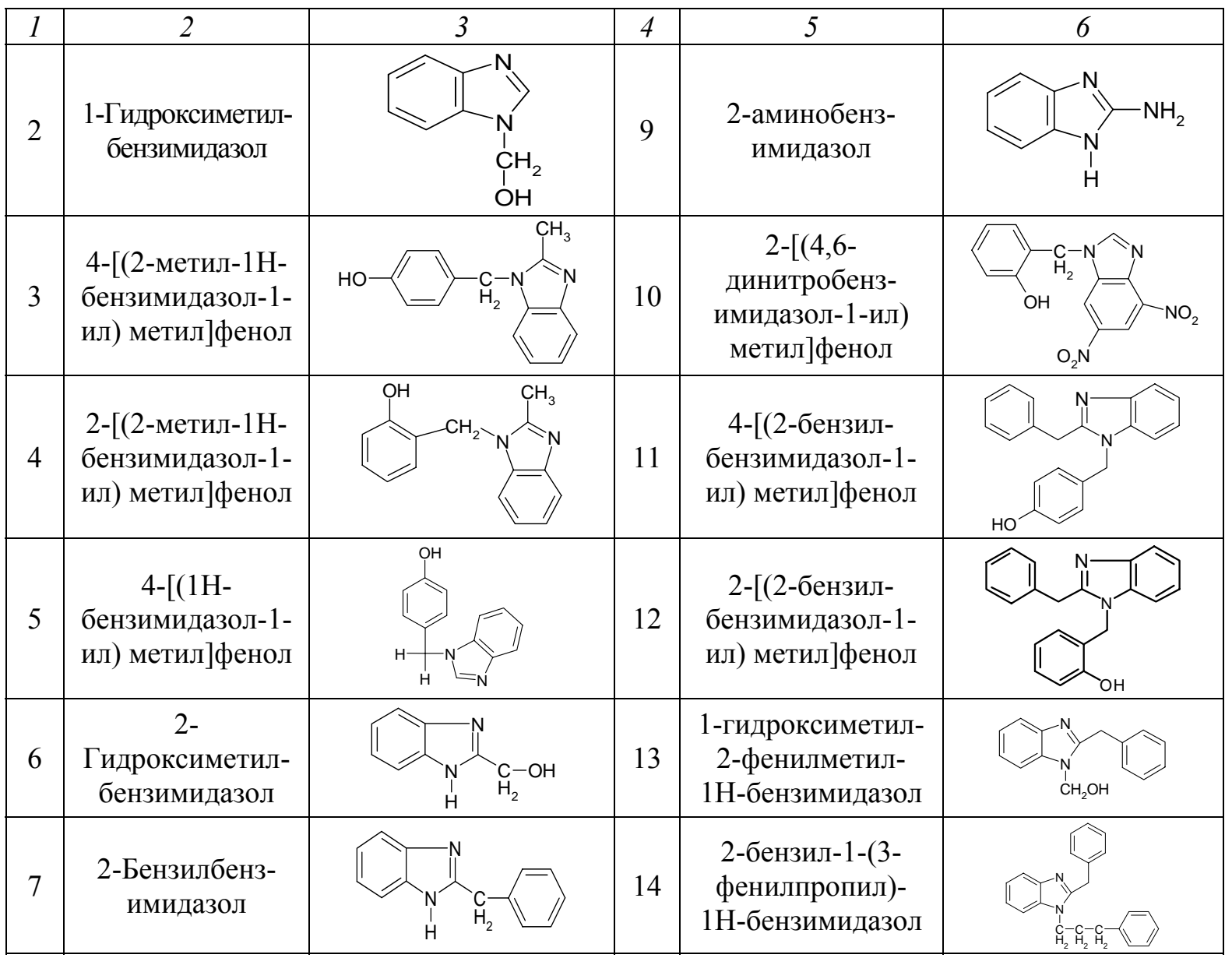

Эксперимент проводили в линейной области изотермы сорбции (области Генри) из сильно разбавленных растворов бензимидазолов. Использовали хроматографическую колонку (120x2 мм), заполненную сорбентом Диасфер $\mathrm{C}_{16}$ с размером зерен - 5 мкм. Удельная площадь поверхности сорбента - $300 \mathrm{~m}^{2} / г$. Эксперимент проводили с использованием жидкостного хроматографа «Милихром А-02» с УФспектрофотометрическим детектором и шприцевым насосом. Детектирование осуществляли при длинах волн 210, 254 и 300 нм. Температуру эксперимента варьировали от 55 до $75^{\circ} \mathrm{C}\left( \pm 0.3^{\circ} \mathrm{C}\right)$. Элюирование осуществляли в изократическом режиме. В качестве подвижной фазы были использованы водно-метанольные элюенты с содержанием метанола 80, 85, 90 и 95\%. Перед началом эксперимента подвижную фазу дегазировали на установке марки УЗДН-2Т. При изменении состава элюента проводили регенерацию хроматографической колонки в течение 30 минут. Объемная скорость подвижной фазы составляла 50 мкл/мин.

Для нахождения взаимосвязи «структура - свойство» проведена оптимизация геометрии производных бензимидазола и рассчитаны поляризуемости, дипольные моменты, установлено распределение электронной плотности в молекулах изучаемых бензимидазолов с применением программного пакета Gaussian 09 методом функционала плотности в базисе $6-311++\mathrm{G}(\mathrm{d}, \mathrm{p})$ с использованием гибридного функционала B3LYP. На основание полученных данных о распределении электронной плотности определены площади поверхности молекул бензимидазолов. Рассчитанные значения молекулярных дескрипторов представлены в табл. 2. 
Таблица 2. Некоторые молекулярные дескрипторы бензимидазолов

\begin{tabular}{|c|c|c|c|}
\hline № & $\begin{array}{c}\text { Площадь поверхности моле- } \\
\text { кулы, }\left(\AA^{2}\right)\end{array}$ & $\begin{array}{c}\text { Дип.момент }(\mu), \\
(\text { Debye })\end{array}$ & Поляризуемость $(\alpha),\left(\mathrm{Bohr}^{3}\right)$ \\
\hline 1 & 141 & 3.54 & 92.45 \\
\hline 2 & 169 & 2.51 & 110.37 \\
\hline 3 & 259 & 2.86 & 192.62 \\
\hline 4 & 258 & 5.22 & 191.28 \\
\hline 5 & 244 & 3.51 & 179.53 \\
\hline 6 & 170 & 2.13 & 112.45 \\
\hline 7 & 238 & 3.71 & 176.49 \\
\hline 8 & 235 & 3.99 & 173.01 \\
\hline 9 & 155 & 4.63 & 105.10 \\
\hline 10 & 286 & 10.09 & 214.68 \\
\hline 11 & 326 & 3.13 & 260.32 \\
\hline 12 & 332 & 4.99 & 260.07 \\
\hline 13 & 257 & 2.84 & 277.44 \\
\hline 14 & 351 & 3.68 & 192.32 \\
\hline
\end{tabular}

*Номера соединений в данной таблице соответствуют нумерации, приведенной в табл. 1.

\section{Обсуждение результатов}

Влияние состава элюента на сорбцию производных бензимидазола в условиях ОФ ВЭЖХ. В рамках модели Снайдера - Сочевинского было исследовано влияние состава подвижной фазы на хроматографическое удерживание. Зависимость в координатах этой модели представлена на рис.1.

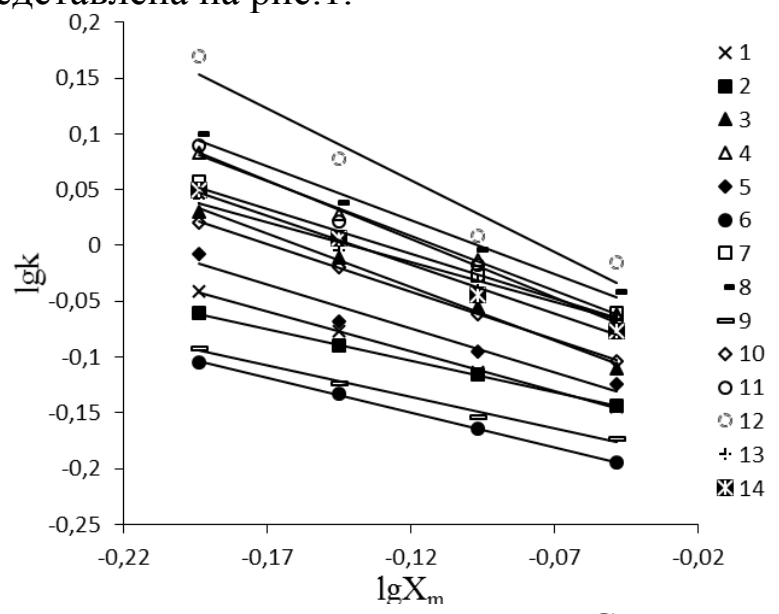

Рис. 1. Зависимости в координатах уравнения Снайдера-Сочевинского для производных бензимидазола (содержание метанола $-95 \div 80$ об. \%; Т=338 К)

Из представленных зависимостей видно, что с увеличением содержания органического модификатора в элюенте сорбция всех исследуемых бензимидазолов на гексадедилсиликагеле снижается. Параметры уравнений Снайдера - Сочевинского для исследуемых соединений представлены в табл.3.

Из табл.3 нетрудно видеть, что зависимости характеризуются высокими коэффициентами детерминированности, следовательно, рассматриваемая модель применима для описания сорбции исследуемых сорбатов в системе «гексадецилсиликагель - водно-метанольный раствор». Также из данных, приведенных в табл. 3 , следует, что с увеличением температуры угловой коэффициент (n) в уравнении Снайдера - Сочевинского для большинства соединений уменьшается, что, очевидно, связано с увеличением десорбции этих соединений. 
Таблица 3. Параметры уравнения Снайдера-Сочевинского для исследуемых бензимидазолов при различных температурах эксперимента

\begin{tabular}{|c|c|c|c|c|c|c|c|c|c|}
\hline \multirow{2}{*}{$\begin{array}{c}\text { Cop- } \\
\text { бат }\end{array}$} & \multicolumn{9}{|c|}{$\operatorname{logk}=\mathrm{a}-\log _{\mathrm{m}}$} \\
\cline { 2 - 11 } & \multicolumn{3}{|c|}{$55^{\circ} \mathrm{C}$} & \multicolumn{3}{c|}{$65^{\circ} \mathrm{C}$} & \multicolumn{3}{c|}{$75^{\circ} \mathrm{C}$} \\
\hline & $\mathrm{a}$ & $|\mathrm{n}|$ & $\mathrm{R}^{2}$ & $\mathrm{a}$ & $|\mathrm{n}|$ & $\mathrm{R}^{2}$ & $\mathrm{a}$ & $|\mathrm{n}|$ & $\mathrm{R}^{2}$ \\
\hline 1 & -0.142 & 0.833 & 0.973 & -0.179 & 0.859 & 0.999 & -0.200 & 0.708 & 0.945 \\
\hline 2 & -0.156 & 0.778 & 0.998 & -0.170 & 0.683 & 0.999 & -0.194 & 0.628 & 0.997 \\
\hline 3 & -0.135 & 1.223 & 0.999 & -0.151 & 1.157 & 0.994 & -0.176 & 0.982 & 0.999 \\
\hline 4 & -0.087 & 1.254 & 0.994 & -0.107 & 1.178 & 0.997 & -0.141 & 1.137 & 0.998 \\
\hline 5 & -0.142 & 1.043 & 0.984 & -0.167 & 0.941 & 0.9631 & -0.208 & 0.977 & 0.994 \\
\hline 6 & -0.189 & 0.729 & 0.985 & -0.223 & 0.749 & 0.999 & -0.257 & 0.818 & 0.978 \\
\hline 7 & -0.082 & 1.039 & 0.990 & -0.101 & 0.962 & 0.987 & -0.124 & 0.772 & 0.999 \\
\hline 8 & -0.086 & 1.360 & 0.994 & -0.091 & 1.163 & 0.988 & -0.115 & 1.092 & 0.997 \\
\hline 9 & -0.198 & 0.803 & 0.992 & -0.202 & 0.677 & 0.993 & -0.234 & 0.712 & 0.967 \\
\hline 10 & -0.117 & 1.060 & 0.998 & -0.143 & 1.027 & 0.999 & -0.187 & 1.052 & 0.993 \\
\hline 11 & -0.104 & 1.369 & 0.985 & -0.118 & 1.263 & 0.989 & -0.135 & 1.185 & 0.993 \\
\hline 12 & -0.077 & 1.722 & 0.923 & -0.093 & 1.548 & 0.945 & -0.120 & 1.455 & 0.983 \\
\hline 13 & -0.072 & 0.873 & 0.983 & -0.099 & 0.853 & 0.988 & -0.115 & 0.709 & 0.956 \\
\hline 14 & -0.099 & 1.130 & 0.993 & -0.121 & 1.063 & 0.994 & -0.141 & 0.996 & 0.990 \\
\hline
\end{tabular}

*Номера соединений в данной таблице соответствуют нумерации, приведенной в табл. 1.

Молекулы сорбатов 11 и 12, имеющие сравнительно большие площади поверхности и значения поляризуемости ( $\mathrm{S}=326 \AA^{2} ; \alpha=260 \mathrm{Bohr}^{3}$ и $\mathrm{S}=332 \AA^{2}, \alpha=260$ $\mathrm{Bohr}^{3}$ соответственно) характеризуются высокими значениями угловых коэффициентов $n$. Это свидетельствует о том, что объемные молекулы сорбатов вытесняют большее количество молекул модификатора с поверхности гексадецилсиликагеля. Тем не менее, сорбат 14 имеющий самое большое значение площади поверхности $\left(\mathrm{S}=352 \AA^{2}\right)$ из всех рассматриваемых бензимидазолов, характеризуется наименьшими значениями $\mathrm{n}$ по сравнению с сорбатами 11 и 12. Скорее всего, это связано с конформационной подвижностью молекулы соединения 14, которая не позволяет ему ориентироваться таким образом, чтобы вытеснять наибольшее количество молекул модификатора с поверхности сорбента. Наименьшими угловыми коэффициентами характеризуются сорбаты 2, 6 и 9. Очевидно, это связано с наличием в их структуре гидроксиметиленовых групп (сорбат 2, сорбат 6) и аминогруппы (сорбат 9), которые усиливают специфические взаимодействия с компонентами подвижной фазой, и, следовательно, сорбция этих молекул на поверхности гексадецилсиликагеля снижается.

Установлено, что соединение 10, обладающее самым высоким значением дипольного момента ( $\mu=10.0903 \mathrm{D})$, характеризуется угловым коэффициентом $\mathrm{n}$ сопоставимым с угловыми коэффициентами бензимидазолов, имеющих средние значения дипольных моментов. Вероятно, это связано с тем, что для этого соединения имеет место внутримолекулярные взаимодействия между гидроксильной группой и нитрогруппой, что приводит к снижению специфических взаимодействий в системе.

В работе количественно оценены энергетические вклады различных заместителей в процесс сорбции, на основе разности изменений энергии Гиббса сорбции всех исследуемых сорбатов. В качестве стандарта использовали бензимидазол (сорбат 1). 
Из представленных зависимостей видно, что положительный вклад в энергию сорбции вносят гидрофильные заместители сорбатов 9 (аминогруппа), 2 и 6 (гидроксиметиленовые группы). Это связано с тем, что вышеприведенные заместители способны усилить специфические взаимодействия с полярной подвижной фазой. Необходимо отметить, что наличие незамещенного пиррольного атома азота (соединения 6 и 9), который является кислотным центром молекулы, значительно заметнее снижает энергию сорбции исследуемых сорбатов, по сравнению с соединениями, где вместо атома водорода находится заместитель (сорбат 2). Сорбаты 12, 8 и 11 характеризуются наибольшими значениями $\delta\left(\Delta G^{o}\right)_{i, s t}$. Это, по-видимому, связано с наличием в их молекулах объемных гидроксибензильных и бензильных заместителей, которые увеличивают вклад дисперсионных взаимодействий этих молекул с поверхностью гексадецилсиликагеля. Из графика видно, что пара-изомер 11 сорбируется заметно меньше, чем орто-изомер 12. Скорее всего это связано с внутримолекулярными взаимодействиями гидроксильной группы и $\pi$-электронов бензольного кольца, что снижает вклад специфических взаимодействий в энергию сорбции. Аналогичная ситуация наблюдается для сорбатов 3 и 4. Соединение 5 удерживается меньше, в отличие от сорбатов 3 и 4, которые содержат гидрофобные метильные группы.

В целом, для большинства соединений с увеличением процентного содержания органического модификатора в элюенте, значения разностей энергии Гиббса снижаются по абсолютной величине, что свидетельствует об уменьшении гидрофобного вытеснения молекул сорбата из элюента на поверхность гексадецилсиликагеля (рис. 2).

Влияние температуры на удерживание. Энтальпийно - энтропийная компенсация. С увеличением температуры факторы удерживания для всех изучаемых бензимидазолов закономерно уменьшаются. Установлено, что при варьировании температуры селективность разделения практически не изменяется (рис.3).

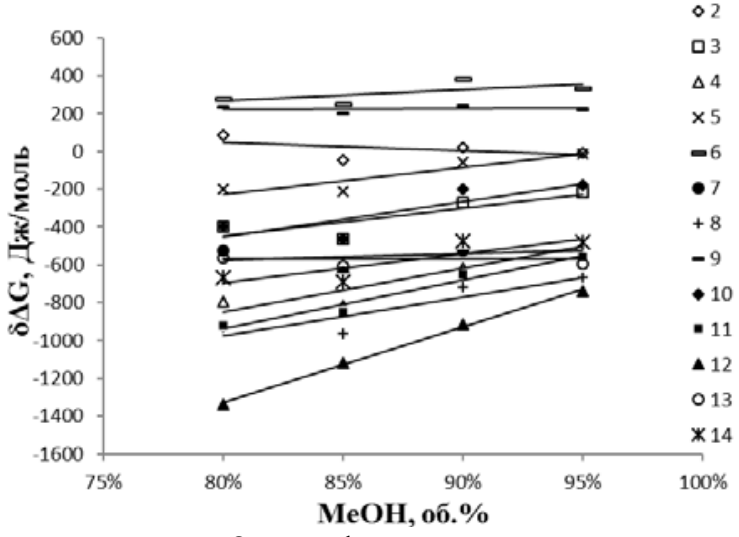

Рис. 2. График зависимостей разностей энергий Гиббса сорбции исследуемых производных бензимидазола от различного содержания органического модифиатора $(\mathrm{T}=348 \mathrm{~K})$

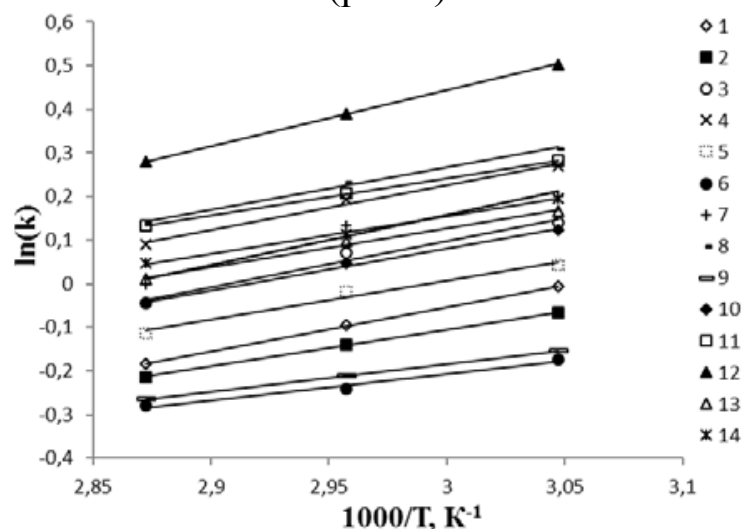

Рис. 3. Температурные зависимости фактора удерживания для бензимидазолов (подвижная фаза 80/20 - метанол/вода, об\%).

На основании температурных зависимостей факторов удерживания определяли значения энтальпий и энтропийных составляющих. Достоверность расчетов подтверждается высокими значениями коэффициентов детерминированности этих зависимостей. Значения энтальпий и энтропийных составляющих процесса сорбции исследуемых бензимидазолов, а также коэффициенты детерминированности зависимостей, из которых рассчитаны эти величины представлены в табл.4. 
Низкие значения величин энтальпий в таблице 4 связаны с тем, что сорбция из водно-органических растворов на различных поверхностях является сложным процессом, связанным с сольватацией в объемной фазе, десольватацией и конкурентной сорбцией в фазе сорбента [15], и являются результирующими величинами

Таблица 4. Значение энтальпий, энтропийных составляющих и коэффициентов детерминированности зависимостей

\begin{tabular}{|c|c|c|c|c|c|c|c|c|c|c|c|c|}
\hline $\begin{array}{c}\text { Фаза } \\
\mathrm{MeOH} /\end{array}$ & \multicolumn{3}{|c|}{$80 / 20$} & \multicolumn{3}{|c|}{$85 / 15$} & \multicolumn{3}{|c|}{$90 / 10$} & \multicolumn{3}{|c|}{$95 / 5$} \\
\hline Сорбат & $\begin{array}{l}\Delta \mathrm{H}^{\circ}, \\
\text { кДж/ } \\
\text { моль }\end{array}$ & $|A|$ & $\mathrm{R}^{2}$ & $\begin{array}{l}\Delta \mathrm{H}^{\circ}, \\
\text { кДж/ } \\
\text { моль }\end{array}$ & $|\mathrm{A}|$ & $\mathrm{R}^{2}$ & $\begin{array}{l}\Delta \mathrm{H}^{\circ}, \\
\text { кДж/ } \\
\text { моль }\end{array}$ & $|\mathrm{A}|$ & $\mathrm{R}^{2}$ & $\begin{array}{l}\Delta \mathrm{H}^{\circ}, \\
\text { кДж/ } \\
\text { моль }\end{array}$ & $|\mathrm{A}|$ & $\mathrm{R}^{2}$ \\
\hline 1 & 8.40 & 3.08 & 1.00 & 8.25 & 3.14 & 0.95 & 6.88 & 2.71 & 1.00 & 7.04 & 2.83 & 0.99 \\
\hline 2 & 6.58 & 2.48 & 1.00 & 6.50 & 2.53 & 0.99 & 5.87 & 2.36 & 1.00 & 4.98 & 2.11 & 0.99 \\
\hline 3 & 8.79 & 3.07 & 0.98 & 7.25 & 2.63 & 0.92 & 6.68 & 2.53 & 0.92 & 5.45 & 2.20 & 0.99 \\
\hline 4 & 8.52 & 2.85 & 0.99 & 6.71 & 2.33 & 0.99 & 6.22 & 2.25 & 0.98 & 6.99 & 2.64 & 0.98 \\
\hline 5 & 7.39 & 2.66 & 0.98 & 9.77 & 3.61 & 0.97 & 7.85 & 3.01 & 1.00 & 7.01 & 2.80 & 0.95 \\
\hline 6 & 5.02 & 2.02 & 0.98 & 7.11 & 2.84 & 1.00 & 7.89 & 3.18 & 1.00 & 6.03 & 2.59 & 1.00 \\
\hline 7 & 9.59 & 3.30 & 0.96 & 7.30 & 2.59 & 0.99 & 7.21 & 2.63 & 0.99 & 5.73 & 2.19 & 0.97 \\
\hline 8 & 8.12 & 2.66 & 1.00 & 6.21 & 2.11 & 0.99 & 5.24 & 1.88 & 0.97 & 4.49 & 1.71 & 0.94 \\
\hline 9 & 5.22 & 2.07 & 1.00 & 5.60 & 2.29 & 0.93 & 4.50 & 1.96 & 0.99 & 4.22 & 1.92 & 0.88 \\
\hline 10 & 8.01 & 2.81 & 1.00 & 7.02 & 2.55 & 0.98 & 8.51 & 3.19 & 0.97 & 7.39 & 2.88 & 0.99 \\
\hline 11 & 7.05 & 2.30 & 1.00 & 5.38 & 1.86 & 1.00 & 4.79 & 1.75 & 0.98 & 4.55 & 1.77 & 1.00 \\
\hline 12 & 10.66 & 3.40 & 1.00 & 7.47 & 2.49 & 0.99 & 3.99 & 1.39 & 0.97 & 7.94 & 2.87 & 0.98 \\
\hline 13 & 7.43 & 2.55 & 0.99 & 6.64 & 2.38 & 1.00 & 6.75 & 2.48 & 0.99 & 4.99 & 1.91 & 0.98 \\
\hline 14 & 7.08 & 2.40 & 1.00 & 5.89 & 2.09 & 0.99 & 6.29 & 2.33 & 1.00 & 4.99 & 1.95 & 1.00 \\
\hline
\end{tabular}

На рисунке 4 представлена взаимосвязь между энтальпией и объемом молекул бензимидазолов.

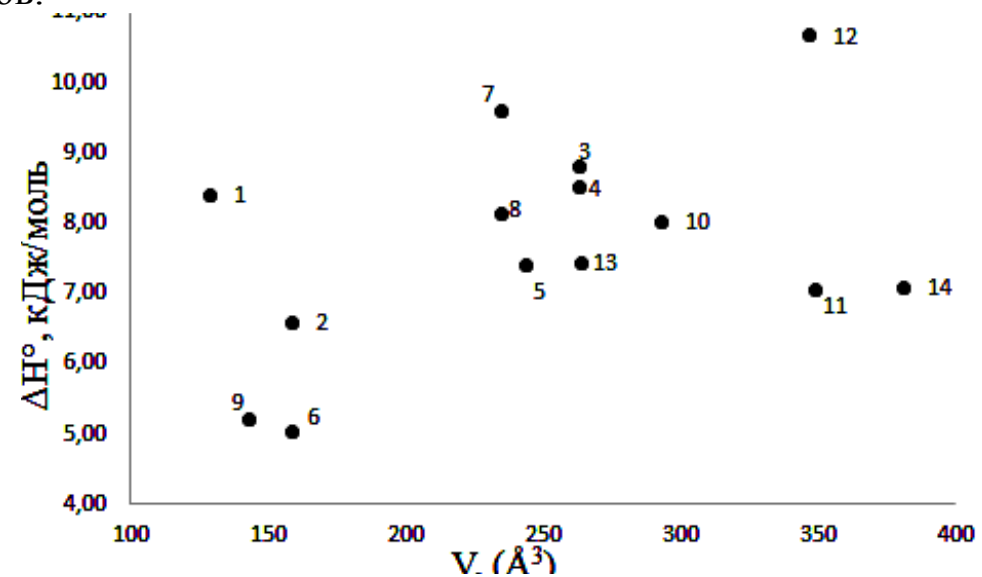

Рис. 4. Взаимосвязь между энтальпией и объемом молекул бензимидазолов.

Из рисунка 4 нетрудно видеть, что для большинства сорбатов значения энтальпий лежат в диапазоне от 6 до 9 кДж/моль. Низкими значениями характеризуются молекулы сорбатов 6 и 9, имеющие низкие значения объемов. Соединения 11 и 12 являются структурными изомерами, содержащими гидрофобные бензильные и гид- 
роксибензильные заместители. Сорбат 12 (орто-изомер) характеризуется высоким значением энтальпии (кДж/моль). Вероятно это связано с тем, что гидроксильная группа в пара-положении усиливает специфические взаимодействия с компонентами подвижной фазы и, соответственно, энергия взаимодействия с неполярным гексадецилсиликагелем будет снижаться. Объемный сорбат 14 имеет то же значение энтальпии, что и сорбат 11 , имеющий значительно меньший объем молекулы. Это связано с тем, что его сорбция на поверхности гексадецилсиликагеля должна будет сопровождаться заметным эндотермическим эффектом связанным с его десольватацией в подвижной фазе. Значительный вклад в суммарную энергию взаимодействия будет также вносить конкурентная сорбция в слое гексадецилсиликагеля.

Исследование компенсационного эффекта сорбции производных бензимидазола. Найдены зависимости между энтальпией и энтропийной составляющей, указывающие на общность механизмов сорбции, исследуемых бензимидазолов. Был оценен энтальпийно-энтропийный компенсационный эффект описываемый уравнением (6). На рис.5 представлены энтальпийно-энтропийные зависимости процесса сорбции из элюента с различным содержанием органического модификатора.
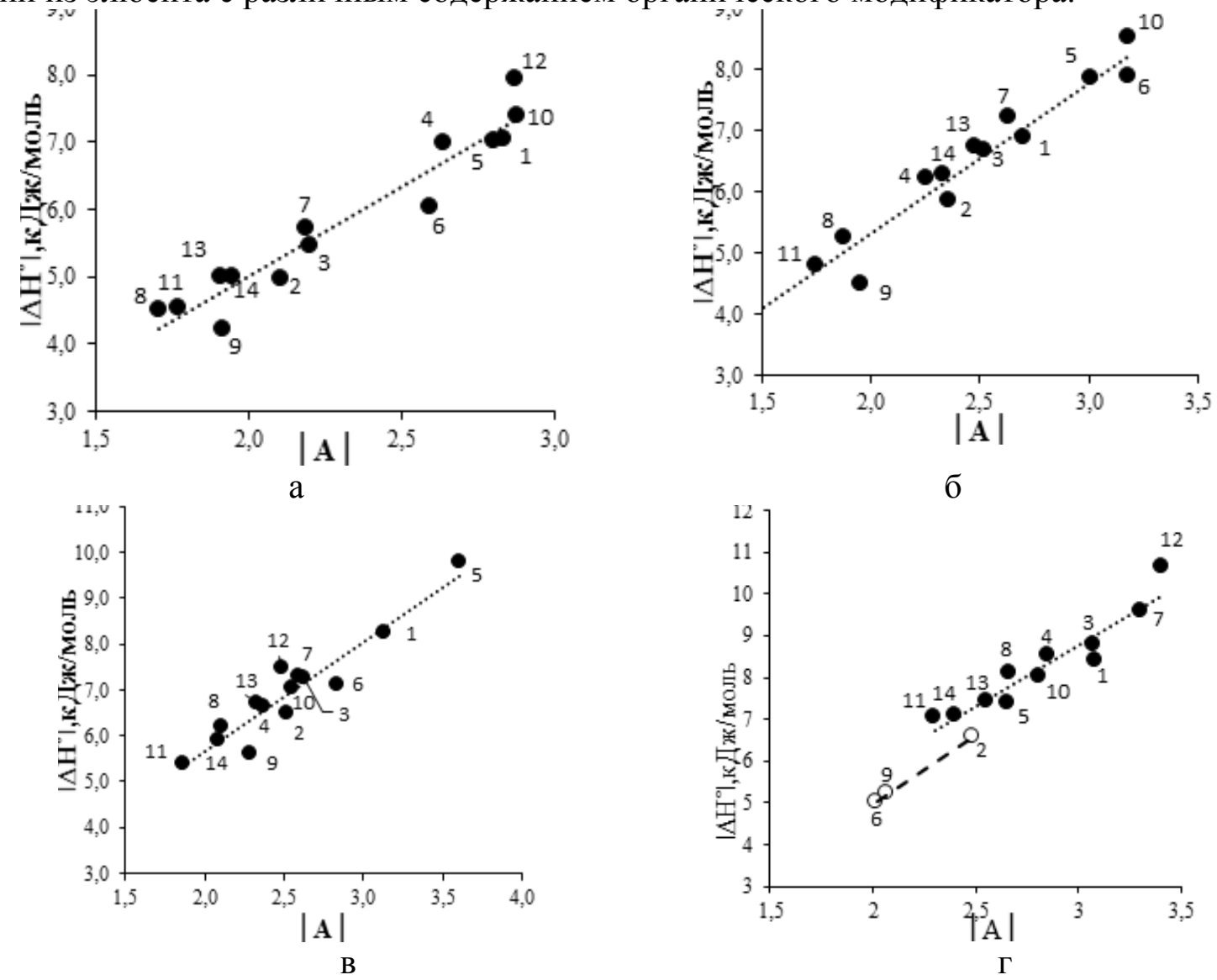

Рис. 5. Энтальпийно-энтропийная зависимость процесса перехода бензимидазолов из водно-метанольного раствора в фазу гексадецилсиликагеля. а - 95 об. \% содержание метанола; б - 90 об. \% содержание метанола; в - 85 об. \% содержание метанола; г - 80 об. \% содержание метанола

В работах $[3,16]$ установлено влияние состава подвижной фазы на энтальпийно-энтропийную компенсацию, в которых показано, что с увеличением содержания воды в элюенте механизмы сорбции рассматриваемых соединений становятся несколько различными. Энальпийно-энтропийный компенсационный эффект для исследуемых сорбатов наблюдался в основном для всех составов элюента; однако, с 
увеличением содержания воды в элюенте до 80\% выделяется две группы сорбатов, из которых можно выделить компенсационную зависимость для сорбатов 2, 6 и 9, которые имеют в своей структуре гидрофильные гидроксиметиленовые группы и аминогруппу. Это говорит о том, что их механизм сорбции несколько отличается от других бензимидазолов.

\section{Заключение}

Таким образом, в настоящей работе получены следующие новые данные в области сорбции бензимидазолов из водно-метанольных растворов на гексадецилсиликагеле:

-изучено влияние состава водно-метанольного раствора на сорбцию бензимидазолов на поверхности гексадецилсиликагеля. Получены соответствующие уравнения в рамках модели Снайдера-Сочевинского;

- рассчитаны энергетические вклады различных заместителей бензимидазолов в сорбцию на гексадецилсиликагеле;

- рассчитаны стандартные изменения энтальпий и энтропийных составляющих процесса перехода бензимидазолов из водно-метанольного раствора в фазу гексадецилсиликагеля;

- изучены компенсационные зависимости для производных бендимидазолов на подвижных фазах с различным содержанием органического модификатора; показано, что на фазе с 80\%-ным содержанием метанола выделяются две группы сорбатов с различными механизмами сорбции на гексадецилсиликагеле.

Работа выполнена в рамках гранта №4.5883.2017/БЧ

в рамках выполнения госзадания Министерства образования и науки РФ

Авторы выражают свою признательность доченту кафедры органической, биоорганической и медицинской химии Самарского университета Белоусовой 3.П. за предоставленные исследуемые бензимидазоль и сотруднику МНИЦТМ гор. Самара Голову А. А. за проведение расчетов физико-химических параметров исследуемых сорбатов в программе Gaussian 0.9

\section{Список литературы}

1. Высоцкий В.И., Рыбин В.Г., Слабко О.Ю., Вербицкий Г.А., Куклев Д.В. // Известия ТИНРО. 2001. Т. 129. С. 52-61.

2. Константинов А. В., Шафигулин Р. В., Ильин М. М., Даванков В. А. и др. // Журнал физической химии. 2013. Т. 87. № 6, С. 10491052.

3. Шафигулин Р. В., Сафронова И.А., Краснова М.С., Буланова А.В. // Физикохимия поверхности и защита материалов. 2015. T. 51. № 3. C. 263-268.

4. Shafigulin R.V., Myakishev A.A., Il'ina E.A., Il'in M.M. et al. // Russian Journal of Physical Chemistry A. 2011. Vol. 85. No 7. pp. 1216-1221.
5. Rakesh K. Patel, Vishal R. Patel, Madhavi G. // Journal of Pharmaceutical Analysis. Vol. 2. Iss. 5. 2012. pp. 366-371.

6. Abolfazl Rahmani-Sani, Ahmad Hosseini-Bandegharaei, Seyyed-Hossein Hosseini, Keivan Kharghani et al. // Journal of Hazardous Materials. 2015. Vol. 286. pp. 152163.

7. Hosseini-Bandegharaei A., Hosseini M.S., Jalalabadi Y., Sarwghadi M. et al. // Intern. J. Environ. Anal. Chem. 2013. Vol. 93. pp. 108-124.

8. Шафигулина А.Д., Ларионов О.Г., Ревина А.А., Пономарёв К.В. и др. // Сорбиионные и хроматографические проиессы. 2013. T. 13. № 6. C. 920-927. 
9. Шатц В.Д., Сахартова О.В. Высокоэффективная жидкостная хроматография: Основы теории. Методология. Применение в лекарственной химии Рига. Зинатне. 1988. $390 \mathrm{c}$.

10. Константинов А.В. авт. дисс. канд. хим. наук. Саратов. 2013. 22 с.

11. Буланова А.В., Полякова Ю.Л. Хроматография в медицине и биологии: учебное пособие Федер. агенство по образованию. Самара. Изд-во «Самарский университет». 2006., 116 c.

12. Сорокин А.А., Гарькин В.П., Елисеева Е.В., Редькин Н.А. и др. // Сорбционные и хроматографические проиессы. 2014. Т. 14. № 4. C. 555-562.

13. Шафигулин Р.В., Буланова А.В. // Журнал физической химии. 2018. Т. 92. № 2. C. $202-208$

14. Krug R.R., Hunter W.G., Grieger R.A. // J. Phys. Chem. 1976. Vol. 80. pp. 2335.

15. Нецкина О.В. Адсорбция из растворов на твердой поверхности Новосибирск. НГУ. 2015. $17 \mathrm{c}$.

16. Шафигулин Р.В., Константинов А.В., Буланова А.В., Ильин М.М. и др. // Журнал физической химии. 2016. Т. 90. № 11. С. 1729-1733.

\section{References}

1. Vysockij V.I., Rybin V.G., Slabko O.Ju., Verbickij G.A., Kuklev D.V., Izvestija TINRO, 2001, Vol. 129, pp. 52-61.

2. Konstantinov A. V., Shafigulin R. V., Il'in M. M., Davankov V. A., Bulanova A. V,. Purygin P.P Sorbcija nekotoryh izatinov na razlichnyh sorbentah v uslovijah OF VJeZhH, Russian Journal of Physical Chemistry A, 2013, T. 87, № 6, P. 1049-1052

3. Shafigulin R. V., Safronova I.A., Krasnova M.S., Bulanova A.V., Fizikohimija poverhnosti i zashhita materialov, 2015, Vol. 51, No 3, pp. 263-268.

4. Shafigulin R.V., Myakishev A.A., Il'ina E.A., Il'in M.M. et al., Russian Journal of Physical Chemistry A, 2011, Vol. 85, No 7, pp. 1216-1221.

5. Rakesh K. Patel, Vishal R. Patel, Madhavi G., Journal of Pharmaceutical Analysis, 2012, Vol. 2, Iss. 5, pp. 366-371.

6. Abolfazl Rahmani-Sani, Ahmad Hosseini-Bandegharaei, Seyyed-Hossein Hosseini et al., Journal of Hazardous Materials, 2015, Vol. 286, pp. 152-163.

7. Hosseini-Bandegharaei A., Hosseini M.S., Jalalabadi Y., Sarwghadi M. et al., Intern. J. Environ. Anal. Chem, 2013, Vol. 93, pp. 108124.

8. Shafigulina A.D., Larionov O.G., Revina A.A., Ponomarjov K.V. et al., Sorbtsionnye $i$

Ядрова Анастасия Александровна - аспирант кафедры физической химии и хроматографии, Самарский университет, Самара

Писарева Валерия Сергеевна - магистр кафедры физической химии и хроматографии, khromatograficheskie protsessy, 2013, T. 13, № 6, P. 920-927

9. Shatc V.D., Sahartova O.V., Vysokojeffektivnaja zhidkostnaja hromatografija: Osnovy teorii. Metodologija. Primenenie v lekarstvennoj himii , Riga, Zinatne, 1988, 390 p.

10. Konstantinov A.V. Diss. cand. chem. nauk. Saratov, 2013, 22 p.

11. Bulanova A.V., Poljakova Ju.L. Hromatografija $\mathrm{v}$ medicine i biologii: uchebnoe posobie Feder. agenstvo po obrazovaniju. Samara, Izd-vo «Samarskij universitet», 2006, 116 p.

12. Sorokin A.A., Gar'kin V.P., Eliseeva E.V., Red'kin N.A. et al., Sorbtsionnye $i$ khromatograficheskie protsessy 2014, Vol. 14, No 4, pp. 555-562.

13. Shafigulin R.V., Bulanova A.V., Journal of Physical Chemistry A, 2018, Vol. 92, No 2, pp. 202-208.

14. Krug R.R., Hunter W.G., Grieger R.A., J. Phys. Chem, 1976, Vol. 80, pp. 2335.

15. Neckina O.V. Adsorbcija iz rastvorov na tverdoj poverhnosti, Novosibirsk, NGU, 2015, $17 \mathrm{p}$.

16. Shafigulin R.V., Konstantinov A.V., Bulanova A.V., Il'in M.M. et al., Russian Journal of Physical Chemistry A, 2016, Vol. 90, No 11, pp. 1729-1733.

Yadrova Anastasiya A. - the postgraduate student, department of physical chemistry and chromatography, Samara University, Samara, e-mail: yadrovaaa@mail.ru

Pisareva Valerija S. - the student, department of physical chemistry and chromatography, Samara 
Самарский университет, Самара

Шафигулин Роман Владимирович - доцент кафедры физической химии и хроматографии, к.Х.н., Самарский университет, Самара

Буланова Анджела Владимировна - профессор кафедры физической химии и хроматографии, д.х.н., Самарский университет, Самара
University, Samara

Shafigulin Roman Vladimirovich - Ph.D (chemistry), associate prof., department of physical chemistry and chromatography, Samara University, Samara, e-mail: shafiro@mail.ru

Bulanova Andzhela V. - prof., grand Ph.D (chemistry), department of physical chemistry and chromatography, Samara University, Samara, email: av.bul@yandex.ru 